Proceedings

\title{
Trends and Associates of Non-Medical Prescription Opioid Use in Australia
}

\author{
Kaitlyn Harper ${ }^{1}$, Vivian Chiu ${ }^{1,2,3^{*}}$ and Janni Leung ${ }^{1,2,3}$ \\ 1. School of Psychology, The University of Queensland, St Lucia QLD 4072 and Australia \\ 2. National Centre for Youth Substance Use Research, The University of Queensland, 17 Upland Road, St \\ Lucia QLD 4067, Australia \\ 3. National Drug and Alcohol Research Centre, University of New South Wales, 22-32 King St, Randwick \\ NSW 2031, Australia \\ * Correspondence: Vivian Chiu; vivian.chiu@uq.net.au; National Centre for Youth Substance Use Research, \\ 17 Upland Road, St Lucia QLD 4067, Australia
}

\begin{abstract}
Impacts on substance use related harms is a public health issue of concern in the context of the COVID-19 pandemic. This study included 72,586 Australians who participated in the National Drug Strategy Household Surveys in 2010, 2013, and 2016. The national prevalence of the use prescription opioid for non-medical reasons has been increasing, with $3.22 \%$ in $2010,3.45 \%$ in 2013 , and $3.56 \%$ in 2016. Individuals with high levels of psychological distress, socioeconomically disadvantaged and residing in the non-metropolitan area were more likely to have used non-medical prescription opioid. Pre-COVID-19 estimates are to be used in future studies to assess the contextual effect of the pandemic on drug-related harms.
\end{abstract}

Keywords: Non-medical prescription opioid; correlates; determinants; trends; prevalence

Publisher's Note: MDPI stays neutral with regard to jurisdictional claims in published maps and institutional affiliations.

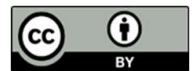

Copyright: (c) 2020 by the authors. Submitted for possible open access publication under the terms and conditions of the Creative Commons Attribution (CC BY) license (http://creativecommons.org/licenses/by/4.0/).

\section{Introduction}

Coronavirus disease 2019 (COVID-19) is causing untold challenges and impacts on substance use related harms is a public health issue of concern. Among people who use opioid, compromised lung function from COVID-19 infection increases risk for overdose and associated mortality among those who use prescription opioid [1]. The economic and social impact (e.g., social disconnectedness, anxiety and depression) may further increase risk of opioid use and barriers to access to health care and recovery support services.

The severe impacts of NMPOU-related harms in the USA led the Centre for Disease Control to include opioid overdose prevention in its 2014 list of top five public health challenges [2]. In Australia, trend studies have reported increases in opioid dispensing since 2006 and the prescription of high-potency opioids has also increased [3].

Given the concerns of NMPOU-related harms, this study aims to provide the national prevalence of NMPOU in Australia, and the associated correlates of NMPOU. This study will provide pre-COVID-19 estimates that could be used for subsequent study to assess the contextual effect of COVID-19 on uses of non-medical prescription opioid.

\section{Materials and Methods}

This cross-sectional study used the National Drug Strategy Household Survey (NDSHS) collected in 2010, 2013 and 2016 ( $\mathrm{N}=72,586$; mean age $=48.77,55.1 \%$ female). The survey was conducted among residential households only using a multistage, stratified area random sample design. This study was exempt from ethics review by the Office of Research Ethics at The University of Queensland because it used existing collections of non-identifiable data. 


\subsection{Measures}

The dependent variable 'recent NMPOU' was defined as nonmedical prescription opioid use (yes/no for painkillers and other opioids) in the past 12 months. The key independent variables were year (2010, 2013 or 2016), sex (male or female), and age. Other covariates examined included Indigenous status, psychological distress, employment status, socio-economic status, area of residence, and history of cancer.

\subsection{Statistical analysis}

We estimated the weighted prevalence of NMPOU. Multiple imputation $(n=5)$ was performed for missing values. Binary logistic regression analyses were performed on recent NMPOU, as compared to no recent NMPOU.

\section{Results}

The national prevalence of the use prescription opioid for non-medical reasons has been increasing, with $3.22 \%$ in $2010,3.45 \%$ in 2013 , and $3.56 \%$ in 2016 . Prevalence increased in those aged 40-49 years from 3.1\% to 4.5\% between 2013 and 2016 (see Appendix A). Adjusted regression results showed that the odds of NMPOU use was significantly higher for Indigenous Australians ( $\mathrm{OR}=1.57[1.28,1.94])$. The higher the level of distress, the higher risk of recent use (moderate level of distress: $\mathrm{OR}=1.63$; [1.47, 1.80]; high level: $\mathrm{OR}=2.83$; $[2.51,3.20]$; and very high level: $\mathrm{OR}=4.06$ [3.47, 4.74]). Risk of recent NMPOU was also higher for people residing in the outer regional, remote and very remote areas (OR=1.15; 95\% CI: 1.02, 1.31), and in people living in the lowest socioeconomic area. Details of the regression results are documented in Table 1.

Table 1. Odds Ratios for Variables Predicting NMPOU for Model 1 and Model 2.

\begin{tabular}{|c|c|c|c|}
\hline & & Model 1 & Model 2 \\
\hline & & OR $(95 \%$ CI) & OR $(95 \%$ CI $)$ \\
\hline Year & 2013 & $1.07[0.97,1.19]$ & $1.08[0.97,1.19]$ \\
\hline (ref: 2010) & 2016 & $1.11^{*}[1.00,1.22]$ & $1.07[0.97,1.18]$ \\
\hline Age & 14-19 years old & $0.71^{* * *}[0.60,0.84]$ & $0.64^{* * *}[0.53,0.77]$ \\
\hline \multirow[t]{5}{*}{ (ref: 20-29 years old) } & 30-39 years old & $0.86^{*}[0.75,0.98]$ & $0.98[0.86,1.12]$ \\
\hline & 40-49 years old & $0.85^{*}[0.75,0.97]$ & $0.95[0.83,1.09]$ \\
\hline & 50-59 years old & $0.74^{* * *}[0.64,0.85]$ & $0.81^{* *}[0.70,0.94]$ \\
\hline & 60-69 years old & $0.80^{* *}[0.69,0.93]$ & $0.98[0.84,1.15]$ \\
\hline & $70+$ years old & $0.83^{*}[0.72,0.96]$ & $1.07[0.90,1.27]$ \\
\hline Sex & Female & $0.98[0.90,1.06]$ & $0.91 *[0.84,1.00]$ \\
\hline \multicolumn{4}{|l|}{ (ref: male) } \\
\hline Indigenous status & Non-Indigenous & - & $1.57^{* * *}[1.28,1.94]$ \\
\hline \multicolumn{4}{|l|}{ (ref: Non-Indigenous) } \\
\hline Psychological distress & Moderate & - & $1.63^{* * *}[1.47,1.80]$ \\
\hline \multirow[t]{2}{*}{ (ref: low) } & High & - & $2.83^{* * *}[2.51,3.20]$ \\
\hline & Very high & - & $4.06^{* * *}[3.47,4.74]$ \\
\hline Employment & Unemployed & - & $1.17[0.97,1.42]$ \\
\hline (ref: employed) & Not in labour force & - & $0.81^{* *}[0.70,0.93]$ \\
\hline
\end{tabular}




\begin{tabular}{|c|c|c|c|}
\hline Income & Low & - & $1.11[0.91,1.35]$ \\
\hline (ref: high) & Middle & - & $1.12[0.98,1.27]$ \\
\hline Education attainment & Did not complete high school & - & $1.22^{* *}[1.06,1.41]$ \\
\hline \multirow[t]{2}{*}{ (ref: high school) } & Certificate / diploma & - & $1.22^{* *}[1.06,1.40]$ \\
\hline & $\begin{array}{l}\text { Bachelor / postgraduate de- } \\
\text { gree }\end{array}$ & - & $0.75^{* *}[0.64,0.89]$ \\
\hline Socioeconomic status & 2nd quintile & - & $0.93[0.83,1.05]$ \\
\hline \multirow[t]{3}{*}{ (ref: 1st quintile) } & 3rd quintile & - & $0.80^{* *}[0.71,0.91]$ \\
\hline & 4th quintile & - & $0.78^{* * *}[0.68,0.89]$ \\
\hline & 5th quintile & - & $0.82^{* *}[0.71,0.94]$ \\
\hline Region & Inner regional & - & $0.94[0.84,1.05]$ \\
\hline (ref: major cities) & $\begin{array}{l}\text { Outer regional / remote / very } \\
\text { remote }\end{array}$ & - & $1.15^{*}[1.02,1.31]$ \\
\hline Cancer & $\begin{array}{l}\text { Recent cancer diagnosis / } \\
\text { treatment }\end{array}$ & - & $1.07[0.84,1.35]$ \\
\hline \multicolumn{4}{|l|}{ (ref: no recent cancer) } \\
\hline
\end{tabular}

\section{Discussion}

Impacts on substance use related harms is a public health issue of concern in the context of the COVID-19 pandemic and hence it is important to quantify levels of use before the pandemic. NMPOU has been increasing in Australia from 2010 to 2016. Although Australia is not on a trajectory to experience the same opioid crisis currently being faced in the USA, misuse of opioid analgesic is a serious problem and measures are needed to prevent this progressing to a public health crisis. In addition, there are population subgroups who are at higher risk of NMPOU than others.

There was a significant increase in the prevalence of recent NMPOU among people aged 40-49 years. While no causal mechanisms could be identified, the emergence of chronic pain and other illnesses around the age of 40-49 years could lead to increases in NMPOU initiated through legitimate medical use. Indeed, four out of five of current heroin users in the USA report that their opioid use began with opioid pain relievers [2].

The existing NMPOU among vulnerable population is of public health concern. NMPOU use was higher for Indigenous Australians, supporting previous findings that Indigenous Australians are over-represented in opioid related harm occurrences [4]. Our results also support previous literature which has reported associations between socioeconomic disadvantage and opioid use, problematic opioid use, and opioid dependence $[5$, 6].

Early evidence shows disproportionate incidence of COVID-19 infection and associated deaths among communities of racial/ethnic minority and socioeconomically disadvantaged populations. These communities are also more likely to have been affected by the economic impact of the COVID-19 outbreak. Given that the same factors are also associated with recent NMPOU in Australia, the additive effects of disparities in COVID-19 and NMPOU may further widen racial/ethnic and socioeconomic inequities in the public health. 
The National Pharmaceutical Drug Misuse Framework for Action (2012-2015) [9] has suggested a range of potential strategies to minimise unnecessary opioid exposure and adverse events, such as improvement of access to pain and addiction services and prescription monitoring system. Since many people who use opioid for non-medical reasons first started with prescription opioid pain relievers, reducing opioid exposure may be the most direct way to reduce pharmaceutical opioid-related harms. Improving the availability of alternative pain management services would provide safer options for patients than initiating opioid medications. However, it is equally important that we provide access for patients who require opioid medications. The states and territories have been adopting real-time prescription monitoring system which provides the patient history of opioid prescriptions to prescribers, to prevent people with multiple prescribers to obtain excessive amount of opioid medications. The effectiveness of the prescribing monitoring system remains uncertain $[10,11]$, with concerns over unintended stigmatisation of patients which may jeopardise their treatments [10]. Further assessment and improvement are needed to enhance patient outcome and safety.

This study is not without limitations. The sample size for Indigenous Australians in the NDSHS sample was smaller than anticipated based on population estimates, and as such the Australian Institute of Health and Welfare (2011) recommend caution when interpreting estimates for this population group. The NDSHS excludes homeless people, people residing in non-private dwellings (e.g. hotels), and people residing in institutional settings (e.g. hospitals, nursing homes, prisons, rehabilitation centres), which may have underestimated the national prevalence of NMPOU.

\section{Conclusions}

In conclusion, the NMPOU remains a serious problem in Australia and the COVID19 pandemic may have worsen opioid use disorders and health in general among who use opioid for non-medical reasons. The present study provides a pre-COVID-19 NMPOU estimates that could be used for future studies to assess the potential impact of the COVID-19 pandemic among the vulnerable population.

Author Contributions: Conceptualisation, K.H. and J.L; methodology, K.H. and J.L.; formal analysis, K.H.; writing - original draft preparation, K.H. and V.C; writing - review and editing, J.L.; supervision, J.L. All authors have read and agreed to the published version of the conference proceeding.

Funding: This research received no external funding.

Acknowledgments: We acknowledge the Australian Social Science Data Archive for reviewing the project protocol, approving the project, and providing the requested data.

Conflicts of Interest: The authors declare no conflict of interest.

\section{References}

[1] N. D. Volkow, "Collision of the COVID-19 and Addiction Epidemics," Ann Intern Med, vol. 173, no. 1, pp. 61-62, Jul 7 2020, doi: 10.7326/M20-1212.

[2] A. Kolodny et al., "The prescription opioid and heroin crisis: a public health approach to an epidemic of addiction," Annu Rev Public Health, vol. 36, pp. 559-74, Mar 18 2015, doi: 10.1146/annurev-publhealth-031914-122957.

[3] E. A. Karanges, B. Blanch, N. A. Buckley, and S. A. Pearson, "Twenty-five years of prescription opioid use in Australia: a whole-of-population analysis using pharmaceutical claims," Br J Clin Pharmacol, vol. 82, no. 1, pp. 255-267, 2016, doi: 10.1111/bcp.12937.

[4] L. Geddes, J. Iversen, S. Memedovic, and L. Maher, "Intravenous fentanyl use among people who inject drugs in Australia: Intravenous fentanyl use among PWID," Drug and alcohol review, vol. 37, pp. S314-S322, 2018, doi: 10.1111/dar.12668.

[5] G. Campbell et al., "Pharmaceutical Opioid Use and Dependence among People Living with Chronic Pain: Associations Observed within the Pain and Opioids in Treatment (POINT) Cohort," Pain Med, vol. 16, no. 9, pp. 1745-1758, 2015, doi: 10.1111/pme.12773. 
[6] L. Degenhardt, N. Gisev, E. Cama, S. Nielsen, B. Larance, and R. Bruno, "The extent and correlates of community-based pharmaceutical opioid utilisation in Australia," Pharmacoepidemiol Drug Saf, vol. 25, no. 5, pp. 521-38, May 2016, doi: 10.1002/pds.3931.

[7] R. L. Haffajee, L. A. Lin, A. S. B. Bohnert, and J. E. Goldstick, "Characteristics of US Counties With High Opioid Overdose Mortality and Low Capacity to Deliver Medications for Opioid Use Disorder," JAMA Netw Open, vol. 2, no. 6, p. e196373, Jun 5 2019, doi: 10.1001/jamanetworkopen.2019.6373.

[8] R. K. Wadhera et al., "Variation in COVID-19 Hospitalizations and Deaths Across New York City Boroughs," JAMA, vol. 323, no. 21, pp. 2192-2195, Jun 2 2020, doi: 10.1001/jama.2020.7197.

[9] (2012). National Pharmaceutical Drug Misuse Framework for Action (2012-2015). . [Online] Available: http://www.nationaldrugstrategy.gov.au/internet/drugstrategy/Publishing.nsf/content/drug-mu-frm-action

[10] G. Campbell, N. Lintzeris, N. Gisev, B. Larance, S. Pearson, and L. Degenhardt, "Regulatory and other responses to the pharmaceutical opioid problem," Med J Aust, vol. 210, no. 1, pp. 6-8.e1, 2018, doi: 10.5694/mja2.12047.

[11] M. Dobbin and D. F. Liew, "Real-time prescription monitoring: helping people at risk of harm," Aust Prescr, vol. 43, no. 5, pp. 164-167, Oct 2020, doi: 10.18773/austprescr.2020.050. 
Appendix A. NMPOU Weighted Prevalence Estimates for each Year by Independent Variable Combination.

\begin{tabular}{|c|c|c|c|c|c|}
\hline & & $\begin{array}{c}2010 \\
N=25,939\end{array}$ & $\begin{array}{c}2013 \\
N=23,414\end{array}$ & $\begin{array}{c}2016 \\
N=23,233\end{array}$ & Chi-square \\
\hline & & $\%(95 \% \mathrm{CI})$ & $\%(95 \% \mathrm{CI})$ & $\%(95 \% \mathrm{CI})$ & p-value \\
\hline Total & & $3.22[3.01,3.44]$ & $3.45[3.22,3.68]$ & $3.56[3.32,3.80]$ & 0.122 \\
\hline \multirow[t]{7}{*}{ Age } & $14-19$ years old & $2.71[2.51,2.91]$ & $3.28[3.05,3.51]$ & $2.75[2.54,2.96]$ & $<0.001$ \\
\hline & 20-29 years old & $4.03[3.79,4.27]$ & $3.95[3.70,4.20]$ & $4.13[3.87,4.39]$ & \\
\hline & 30-39 years old & $3.33[3.11,3.55]$ & $3.91[3.66,4.16]$ & $3.26[3.03,3.49]$ & \\
\hline & $40-49$ years old & $2.68[2.49,2.88]$ & $3.16[2.94,3.39]$ & $4.51[4.24,4.78]$ & \\
\hline & $50-59$ years old & $2.84[2.63,3.04]$ & $3.09[2.87,3.32]$ & $3.10[2.88,3.32]$ & \\
\hline & $60-69$ years old & $3.02[2.82,3.23]$ & $3.73[3.49,3.97]$ & $3.05[2.83,3.28]$ & \\
\hline & $70+$ years old & $3.80[3.57,4.03]$ & $2.77[2.56,2.98]$ & $3.56[3.33,3.80]$ & \\
\hline \multirow[t]{2}{*}{ Sex } & Male & $3.10[2.89,3.31]$ & $3.55[3.32,3.79]$ & $3.69[3.45,3.93]$ & 0.195 \\
\hline & Female & $3.34[3.13,3.56]$ & $3.34[3.11,3.57]$ & $3.43[3.19,3.66]$ & \\
\hline \multirow[t]{2}{*}{ Indigenous status } & Indigenous & $5.41[5.13,5.68]$ & $5.64[5.35,5.94]$ & $8.56[8.20,8.92]$ & $<0.001$ \\
\hline & Non-Indigenous & $3.18[2.97,3.40]$ & $3.41[3.18,3.64]$ & $3.42[3.18,3.65]$ & \\
\hline \multirow[t]{4}{*}{ Psychological distress } & Low & $2.49[2.30,2.68]$ & $2.44[2.24,2.63]$ & $2.66[2.46,2.87]$ & $<0.001$ \\
\hline & Moderate & $3.57[3.34,3.79]$ & $4.10[3.84,4.35]$ & $4.32[4.06,4.58]$ & \\
\hline & High & $7.03[6.72,7.34]$ & $7.26[6.93,7.60]$ & $6.62[6.30,6.94]$ & \\
\hline & Very high & $8.61[8.27,8.95]$ & $12.24[11.82,12.66]$ & $8.54[8.18,8.90]$ & \\
\hline \multirow[t]{3}{*}{ Employment } & Employed & $2.92[2.71,3.12]$ & $3.38[3.15,3.61]$ & $3.74[3.49,3.98]$ & $<0.001$ \\
\hline & Unemployed & $4.95[4.68,5.21]$ & $5.57[5.28,5.87]$ & $5.33[5.05,5.62]$ & \\
\hline & Not in labour force & $3.45[3.23,3.67]$ & $3.27[3.05,3.50]$ & $3.03[2.81,3.25]$ & \\
\hline \multirow[t]{3}{*}{ Income } & Low & $3.65[3.43,3.88]$ & $3.65[3.41,3.89]$ & $3.57[3.33,3.81]$ & $<0.001$ \\
\hline & Middle & $3.44[3.22,3.66]$ & $3.78[3.54,4.03]$ & $3.84[3.59,4.08]$ & \\
\hline & High & $2.37[2.19,2.56]$ & $2.96[2.74,3.18]$ & $3.24[3.01,3.46]$ & \\
\hline \multirow[t]{4}{*}{ Education attainment } & Did not complete high school & $3.54[3.31,3.76]$ & $3.94[3.69,4.19]$ & $3.99[3.74,4.24]$ & $<0.001$ \\
\hline & High school & $3.23[3.01,3.44]$ & $3.10[2.88,3.32]$ & $3.54[3.30,3.78]$ & \\
\hline & Certificate / diploma & $3.57[3.34,3.80]$ & $4.10[3.84,4.35]$ & $4.29[4.02,4.55]$ & \\
\hline & Bachelor / postgraduate degree & $2.32[2.13,2.50]$ & $2.33[2.14,2.53]$ & $2.32[2.13,2.52]$ & \\
\hline
\end{tabular}




\begin{tabular}{|c|c|c|c|c|c|}
\hline Socioeconomic status & 1st quintile (most disadvantaged) & $4.01[3.78,4.25]$ & $4.35[4.09,4.61]$ & $4.78[4.50,5.05]$ & $<0.001$ \\
\hline & 2nd quintile & $3.96[3.72,4.20]$ & $3.63[3.39,3.87]$ & $3.95[3.70,4.21]$ & \\
\hline & 3rd quintile & $2.74[2.54,2.94]$ & $3.17[2.94,3.39]$ & $3.60[3.36,3.84]$ & \\
\hline & 4th quintile & $2.90[2.70,3.10]$ & $3.06[2.84,3.28]$ & $2.81[2.60,3.03]$ & \\
\hline & 5th quintile (least disadvantaged) & $2.68[2.48,2.87]$ & $3.20[2.98,3.43]$ & $2.59[2.39,2.80]$ & \\
\hline \multirow[t]{3}{*}{ Region } & Major cities & $3.11[2.90,3.32]$ & $3.34[3.11,3.57]$ & $3.32[3.09,3.55]$ & $<0.001$ \\
\hline & Inner regional & $3.15[2.94,3.36]$ & $3.25[3.02,3.47]$ & $3.82[3.58,4.07]$ & \\
\hline & Outer regional / remote / very remote & $4.05[3.81,4.29]$ & $4.41[4.15,4.67]$ & $4.61[4.34,4.88]$ & \\
\hline \multirow[t]{2}{*}{ Cancer } & Recent cancer diagnosis / treatment & $2.78[2.58,2.97]$ & $4.85[4.58,5.13]$ & $3.66[3.42,3.90]$ & $.101-.187$ \\
\hline & No recent cancer diagnosis / treatment & & & & \\
\hline
\end{tabular}

